\title{
Omega-3 on the fly: long-legged fly Machaerium maritimae as a potential source of eicosapentaenoic acid for aquafeeds
}

\author{
P.M. Duarte ${ }^{1}$, E. Maciel ${ }^{1,2}$, M. Pinho ${ }^{1}$, M.R. Domingues ${ }^{2,3}$, R. Calado ${ }^{1}$, A.I. Lillebø ${ }^{1}$ and O.M.C.C. Ameixa $^{1 *}$ \\ ${ }^{1}$ ECOMARE, Centre for Environmental and Marine Studies - CESAM, Department of Biology, University of Aveiro, Campus \\ de Santiago, 3810-193 Aveiro, Portugal; ${ }^{2}$ Mass Spectrometry Center, Department of Chemistry, University of Aveiro, Campus \\ de Santiago, 3810-193 Aveiro, Portugal; ${ }^{3}$ ECOMARE, Centre for Environmental and Marine Studies - CESAM, Department \\ of Chemistry, University of Aveiro, Campus de Santiago, 3810-193 Aveiro, Portugal; olga.ameixa@ua.pt
}

Received: 31 August 2020 / Accepted: 22 December 2020

(C) 2021 Wageningen Academic Publishers

OPEN ACCESS CC)

\begin{abstract}
The need for more sustainable aquafeeds has prompted the exploration of insects as potential ingredients. However, commonly reared insects are not satisfactory regarding their fatty acid composition, lacking omega-3 long chain polyunsaturated fatty acids (n-3 LC PUFA), important nutrients for marine organisms. In this study, we present in detail the fatty acid profile of the long-legged fly Machaerium maritimae Haliday (Diptera: Dolichopodidae), an amphibiotic insect native to European coastal habitats. Specimens of this fly were collected in Ria de Aveiro coastal lagoon (Portugal) and the fatty acid profile was analysed through gas chromatography coupled with mass spectrometry. Results revealed a remarkably high level of n-3 LC PUFA, $(11 \mu \mathrm{g} / \mathrm{mg}$ dry weight, $20 \%$ of the fatty acid profile) namely eicosapentaenoic acid, and a low level of saturated fatty acids. This value is higher than what is found in Hermetia illucens (black soldier fly), while comparable to other aquatic insects. We also report the presence of 50 distinct fatty acids, including multiple branched-chain and PUFA, and discuss potential implications of their presence on the ecology of this species. Variation in the fatty acid profile along the landscape is also presented. Our results indicate that $M$. maritimae can potentially be a high-quality lipid source for marine aquafeeds. Current legislation in Europe allowing the use of insects in aquaculture is restricted to a few selected species, often non-native, however, further research should consider native insects as potential alternatives to current ingredients in aquafeed.
\end{abstract}

Keywords: coastal insects, Diptera, Dolichopodidae, fatty acids, novel ingredients

\section{Introduction}

With a global population expected to surpass 9.7 billion by 2050 (DESA UN, 2017), the demand for limited resources, such as energy and food, will increase accordingly. Regarding food security, it is estimated that the demand for animal origin products will double, not only due to the increased population, but also to the improvement of economic conditions (FAO/WHO, 2019).

Aquaculture is the food production system which is benefiting the most from this increasing demand, compensating for the apparent stagnation in fisheries (FAO, 2020). However, the high dependence on marine ingredients for feed production (i.e. fishmeal and fish oil) raises doubts about the long-term sustainability of this activity and its capacity to sustain a growing population. These feed ingredients are the main source of important lipids for cultured fish, specifically omega-3 long chain polyunsaturated fatty acids (LC-PUFA), such as eicosapentaenoic (EPA) and docosahexaenoic (DHA) acids (Henry et al., 2015). These lipids promote various health benefits (Shahidi and Ambigaipalan, 2018), and their inclusion in the diet is essential for farmed fish growth, especially for marine species, and for consumers' own health benefits (FAO, 2020). Other alternatives such as plantbased, animal-based ingredients or single cell protein, do not present all the nutrients required for marine organisms and their intensive production has high environmental impacts or production costs (Ameixa et al., 2020). 
Amongst the alternative feed sources investigated, insects have been suggested as a natural, low-carbon emitting and potentially cost-effective source of high quality proteins and other important nutrients (Ameixa et al., 2020; Henry et al., 2015; Van Huis et al., 2013). It has been demonstrated that insects can be included in fish feeds with positive results, depending on the species used, inclusion rate, and overall composition of the diet (Barroso et al., 2014; Belghit et al., 2019; Dobermann et al., 2017; Sánchez-Muros et al., 2014). Although insect meals are frequently a valid alternative protein sources for fish, their fatty acid profile is often inadequate. Terrestrial insects, typically lack n-3 LC-PUFA, being richer in n-6 PUFA (Makkar et al., 2014; Nogales-Mérida et al., 2019; Rumpold and Schlüter, 2013). To overcome this constraint, the possible solutions are: (1) the manipulation of the fatty acid profile of the insects through their diets, which has been accomplished with some restrictions (Liland et al., 2017; St-Hilaire et al., 2007); or (2) proceed the screening of more viable insect species. The former may not always be economically viable, as $n-3$ rich substrates are expensive and can often be consumed directly by fish (Henry et al., 2015; Stoneham et al., 2018); the second option seems more promising, especially if these new species can efficiently recycle marine wastes that fish cannot (Sánchez-Muros et al., 2014; Tran et al., 2015).

From over 5.5 million insect species estimated to exist worldwide (Stork, 2018), aquatic and amphibiotic (with aquatic larvae and terrestrial, often winged, adults) species have great potential for aquaculture feeds. These have been implicated in nutrient transport from aquatic to terrestrial ecosystems, especially LC-PUFA (Popova et al., 2017; Twining et al., 2018), and their distinct fatty acid profiles might present a viable solution to meet nutritional requirements for fish feed. In addition, these insects are part of the natural diet of fish (Bell et al., 1994; NogalesMérida et al., 2019). The key difference in their fatty acid profile, is the relatively high values of EPA (around 15\%), in comparison with terrestrial insects, which only have trace levels (Bell et al., 1994; Fontaneto et al., 2011; Sushchik et al., 2003; Yang et al., 2006). For this reason, it can be expected that coastal and marine insects may accumulate higher levels of n-3 fatty acids through their diet.

Dolichopodidae are small amphibiotic flies that inhabit a variety of humid environments (Miller et al., 2008), with more than 7500 species described worldwide (Pollet et al., 2019). Many are habitat specialists, well adapted to coastal and estuarine areas, such as mangroves and reed marshes. One of these species is Machaerium maritimae Haliday, a small metallic-green fly widely spread along the northwestern European coast (Pollet et al., 2019). The larvae and pupae of this insect have structural and physiological adaptations to thrive in brackish waters (d'Assis Fonseca,
1978), and the adults are commonly observed moving close or above water, in search of food, from May to September.

In the present study we characterised the fatty acid profile of $M$. maritimae, considering the species spatial distribution, by evaluating if it varied along collection sites in the Ria de Aveiro coastal lagoon (Portugal), a heterogenous mosaic landscape. Results are discussed in the context of the natural diet of this species and its potential as a novel aquafeed ingredient.

\section{Materials and methods}

\section{Study area and experimental design}

The study took place in Ria de Aveiro coastal lagoon (Portugal), characterised by wetlands habitats, e.g. mud and sand flats, seagrasses and salt marshes, classified under the Natura 2000 network and recognised as International Long-Term Ecosystem Research (ILTER) site (Lillebø et al., 2015). The field work was carried out within one-week period in late July 2017. In order to account with the natural spatial variability, the specimens were collected on seven sites along the studied area, most of which are submerged during high tides (Figure 1). The vegetation in these sites is dominated by halophyte species, forming more or less continuous and homogenous patches, depending on the degree of tolerance to submersion and salinity (Asensi and Diez-Garretas, 2017).

Insect specimens were collected on the vegetation, in the selected locations, using sweeping nets (300 sweeps per plant species in each site (Figure 1), and then transferred with an insect aspirator to small flasks, which were preserved at $-80{ }^{\circ} \mathrm{C}$ for later processing. Thus, a distinct number of specimens was collected in each sampling site, reflecting the heterogenous natural distribution of $M$. maritimae in Ria de Aveiro.

\section{Lipid extraction and quantification}

Five representative composed samples $(n=5)$, consisting of 10 individuals each, originating from all sites, were selected exclusively to determine the lipid content (Figure 2). Total lipid extracts were obtained by a modified Folch method (Folch et al., 1957). Briefly, $3 \mathrm{ml}$ 2:1 (v/v) dichloromethane/ methanol and $1 \mathrm{ml}$ ultra-pure water were added to grinded freeze-dried insects, followed by vigorous vortexing and centrifugation ( $5 \mathrm{~min}$ at 2,000 rpm). The organic phase was recovered, and the process was repeated twice, by adding 1 $\mathrm{ml}$ of dichloromethane/methanol, vortex and centrifugation. The lipid content was measured gravimetrically. 

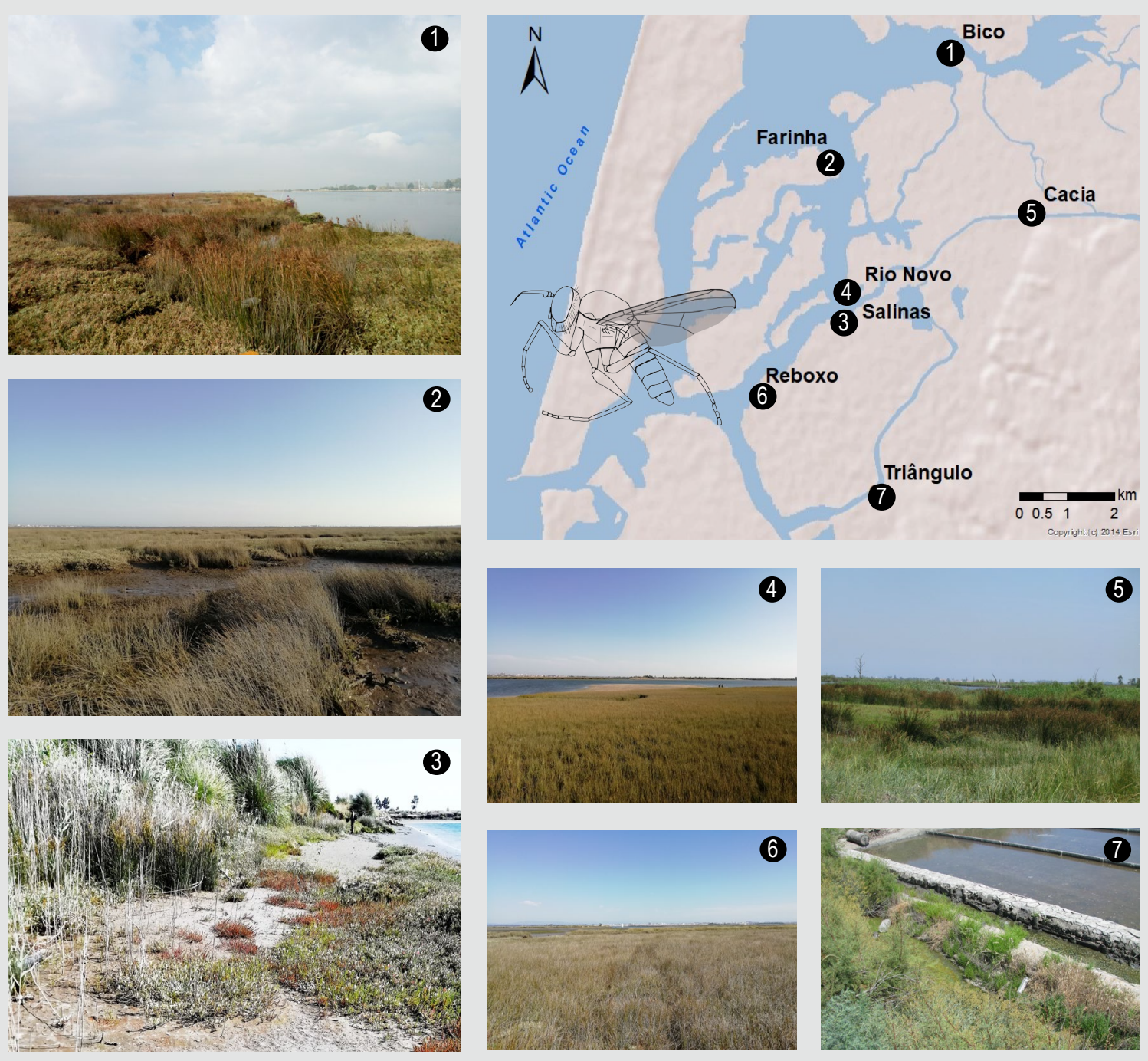

Figure 1. Sampling sites in Ria de Aveiro: (1) Bico $\left(40^{\circ} 43^{\prime} 33.0^{\prime} \mathrm{N} 8^{\circ} 38^{\prime} 46.3^{\prime} \mathrm{W}\right)$ dominated by Halimione portucaloides $\mathrm{L}$. and Juncus maritimus L.; (2) Farinha $\left(40^{\circ} 42^{\prime} 19.3^{\prime} \mathrm{N} 8^{\circ} 40^{\prime} 33.6^{\prime} \mathrm{W}\right)$, dominated by J. maritimus and H. portucaloides; (3) Salinas $\left(40^{\circ} 40^{\prime} 35.0^{\prime} \mathrm{N}\right.$ $8^{\circ} 40^{\prime} 20.0^{\prime} \mathrm{W}$ ), dominated by H. portucaloides, J. maritimus and Sarcocornia perennis (Mill.) A.J. Scott, Phragmites australis (Cav.) Trin ex.Steud.; (4) Rio Novo $\left(40^{\circ} 40^{\prime} 50.8^{\prime} \mathrm{N} 8^{\circ} 40^{\prime} 18.6^{\prime} \mathrm{W}\right)$, dominated by Spartina maritima (Curtis) Fernald; (5) Cacia (40 $41^{\circ} 45.0^{\prime} \mathrm{N}$ $8^{\circ} 37^{\prime} 32.2^{\prime} \mathrm{W}$ ), dominated by J. maritimus, H. portucaloides and Atriplex patula L.; (6) Reboxo (40 $\left.39^{\prime} 42.9^{\prime} \mathrm{N} 8^{\circ} 41^{\prime} 39.9^{\prime} \mathrm{W}\right)$ dominated by H. portucaloides, S. perennis, S. maritima and Limonium vulgare Mill.; and (7) Triângulo $\left(40^{\circ} 38^{\prime} 38.6^{\prime} \mathrm{N} 8^{\circ} 39^{\prime} 54.3^{\prime} \mathrm{W}\right)$ dominated by H. portucaloides, Salicornia ramosissima J. Woods, and Tamarix africana Poir. Map was generated in ArcGIS version 10.6.1.

\section{Fatty acid analysis by gas chromatography-mass spectrometry}

The fatty acids were analysed directly through transmethylation, with no prior extraction, by a procedure adapted from Aued-Pimentel et al. (2004). Samples (1 adult insect per each sample, for a total of 5-20 replicate samples per site; Figure 2 and Table 2) were freeze-dried, weighed (Table 2), grinded to dust and dissolved in $1 \mathrm{ml}$ of $\mathrm{n}$-hexane containing nonadecanoic acid methyl ester as internal standard (C19:0, $2.5 \mu \mathrm{g} / \mathrm{ml})$, followed by $200 \mu \mathrm{l}$ of methanolic solution of $\mathrm{KOH}(2 \mathrm{M})$. The mixture was then well homogenised. Finally, $2 \mathrm{ml}$ of a saturated solution of
$\mathrm{NaCl}$ was added and the mixture was centrifuged at 2,000 $\mathrm{rpm}$ for $5 \mathrm{~min}$. The phase with the fatty acid methyl esters was recovered and $2 \mu \mathrm{l}$ were used as injection volume.

Gas chromatography-mass spectrometry (GC-MS) analysis was conducted in an Agilent Technologies $6890 \mathrm{~N}$ Network (Santa Clara, CA, USA) equipped with a DB-FFAP column, $30 \mathrm{~m}$ of length, $0.32 \mathrm{~mm}$ of internal diameter and 0.25 $\mu \mathrm{m}$ film thickness (J\&W Scientific, Folsom, CA, USA), connected to an Agilent 5973 Network Mass Selective Detector operating with the electron impact mode at 70 $\mathrm{eV}$, scanning range $\mathrm{m} / \mathrm{z}$ 50-550, $1 \mathrm{~s}$ cycle in full scan mode acquisition. Oven temperature was programmed with an 

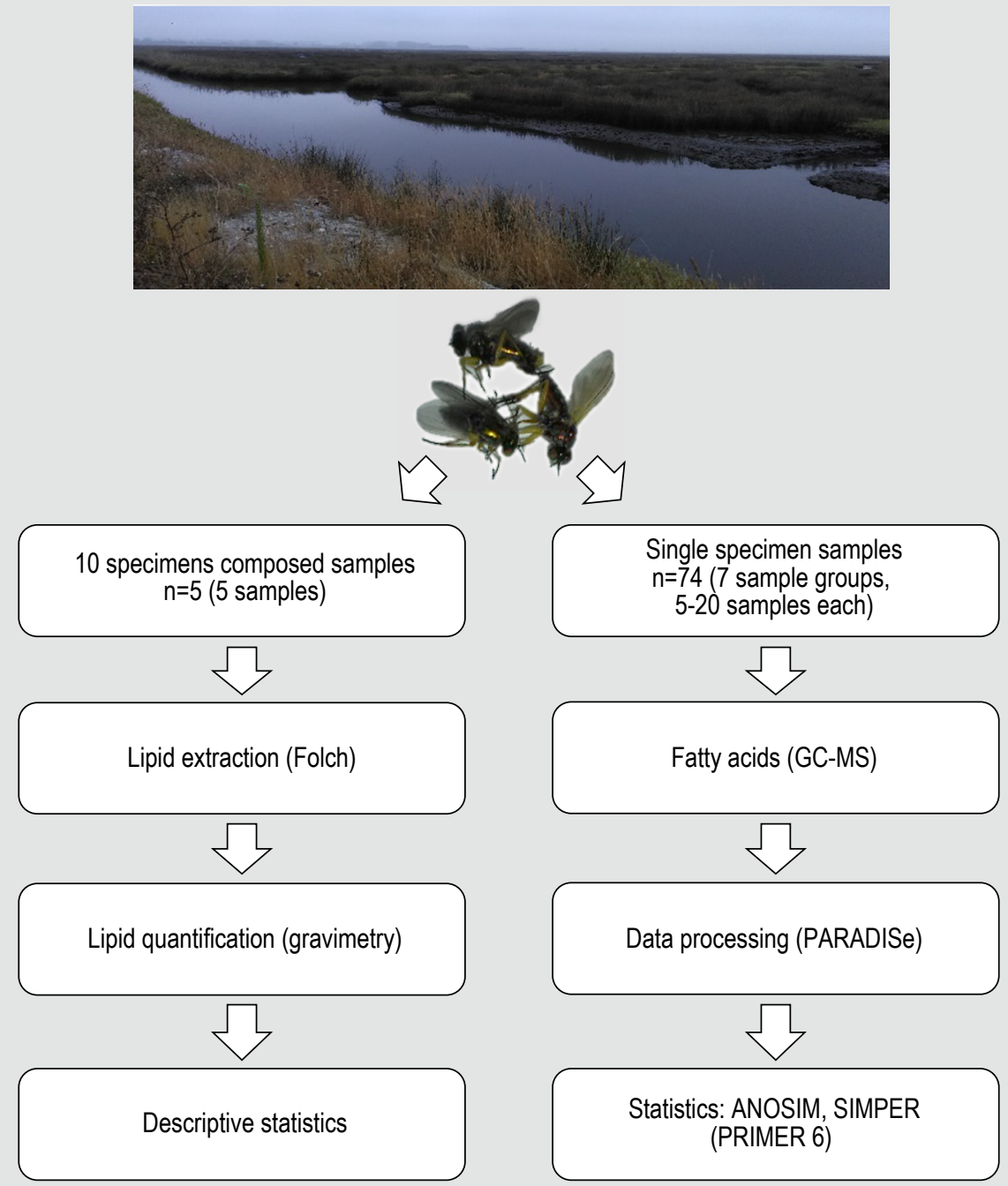

Figure 2. Overview of the workflow applied to the samples used for lipid extraction and to samples used for fatty acids analysis.

initial temperature of $80^{\circ} \mathrm{C}$, with a linear increase at $14.4^{\circ} \mathrm{C} /$ min up to $220^{\circ} \mathrm{C}$, followed by a linear increase at $10^{\circ} \mathrm{C} / \mathrm{min}$ up to $240{ }^{\circ} \mathrm{C}$, and finally $5{ }^{\circ} \mathrm{C} / \mathrm{min}$ to $250^{\circ} \mathrm{C}$. The injector was set to $220^{\circ} \mathrm{C}$ and the detector to $280^{\circ} \mathrm{C}$. Helium was used as carrier gas, at a flow rate of $1.4 \mathrm{ml} / \mathrm{min}$. All solvents were of HPLC grade, purchased from Fisher Scientific (Loughborough, UK).

\section{Data processing and statistical analysis}

Individual fatty acid methyl esters peaks were analysed using PARADISe version 3.87 (Johnsen et al., 2017) and identified by their retention time and using the NIST/EPA/NIH Mass Spectral Library with Search Program, version 2.2 (NIST 14, Gaithersburg, MD, USA). PARADISe is an implementation of the Parallel Factor analysis 2 (PARAFAC2) model, which allows for deconvolution, identification and quantification of chromatographic peaks in all samples simultaneously, enabling measurements of co-eluting and low signal-tonoise ratio chromatographic peaks.

Quantification relative to the internal standard was carried out assuming a response factor of 1 , and values were presented as relative abundances, in percentages. Data used in statistical analysis were those of fatty acids with overall abundance above $0.5 \%$, plus the sum of all branched chain fatty acids (BCFA). Statistical analysis was conducted on PRIMER 6 with PERMANOVA+ add on (Anderson $e t$ al., 2008; Clarke and Gorley, 2006).

Differences between sites were examined with a oneway analysis of similarity (ANOSIM) using a Bray-Curtis dissimilarity matrix on raw (untransformed) data $(\alpha=0.05)$ (Happel et al., 2017). This test calculates a global R statistic, with values close to one meaning high separation between groups, while values closer to zero imply a lower explicatory effect of the factor 'site' (Anderson et al., 2008; Anderson 
and Walsh, 2013; Ricardo et al., 2015). Similarity percentages analysis (SIMPER) was conducted to determine the fatty acids that contributed the most for the dissimilarities between statistically different sites (cut-off $80 \%$ ).

\section{Results}

\section{Lipid extraction and quantification}

The composed samples of ten individuals each $(\mathrm{n}=5,50$ adult $M$. maritimae specimens in total) had $13.16 \pm 0.27$ $\mathrm{mg}$ (SE) in dry weight (DW). These samples yielded lipid extracts containing $1.56 \pm 0.09 \mathrm{mg}$ (SE). Thus, these flies had a lipid content of $12.0 \pm 0.76 \%$ (SE); moreover, each specimen weighted around $1.3 \mathrm{mg}$ and contained around $0.15 \mathrm{mg}$ of lipid.

\section{Fatty acid analysis}

Concerning the samples for GC-MS fatty acid analysis (individual flies collected in the study sites), these weighed (DW) on average $1.26 \pm 0.04 \mathrm{mg}$ (SE). The global fatty acid profile, obtained from these $(n=74)$, was remarkably diverse, encompassing fifty-one different fatty acids (Table 1 ).

Table 1. Full list of the fatty acids identified in $M$. maritimae, mean relative abundance $(\%)$ and absolute quantification ( $\mu \mathrm{g}$ of fatty acid per $\mathrm{mg}$ of insect), $\mathrm{n}=74{ }^{1,2}$

\begin{tabular}{|c|c|c|c|c|c|}
\hline Fatty acid & $\begin{array}{l}\text { Relative abundance } \\
\% \pm \text { SE }\end{array}$ & $\mu \mathrm{g} / \mathrm{mg} \mathrm{DW} \pm \mathrm{SE}$ & Fatty acid & $\begin{array}{l}\text { Relative abundance } \\
\% \pm \mathrm{SE}\end{array}$ & $\mu \mathrm{g} / \mathrm{mg} \mathrm{DW} \pm \mathrm{SE}$ \\
\hline $12: 0$ & $0.097 \pm 0.007$ & $0.067 \pm 0.009$ & $16: 2 n-6$ & $0.102 \pm 0.023$ & $0.085 \pm 0.030$ \\
\hline 13:0 & $0.033 \pm 0.003$ & $0.024 \pm 0.004$ & $18: 2 n-6$ & $3.275 \pm 0.203$ & $1.824 \pm 0.128$ \\
\hline $14: 0$ & $0.870 \pm 0.123$ & $0.690 \pm 0.169$ & $18: 3 n-6$ & $0.375 \pm 0.027$ & $0.251 \pm 0.036$ \\
\hline 15:0 & $0.329 \pm 0.046$ & $0.250 \pm 0.052$ & $20: 2 n-6$ & $0.205 \pm 0.015$ & $0.121 \pm 0.013$ \\
\hline $16: 0$ & $17.131 \pm 0.555$ & $10.448 \pm 0.760$ & $20: 3 n-6$ & $0.220 \pm 0.011$ & $0.127 \pm 0.009$ \\
\hline $17: 0$ & $1.007 \pm 0.086$ & $0.591 \pm 0.071$ & $20: 4 n-6$ & $4.046 \pm 0.214$ & $2.301 \pm 0.148$ \\
\hline 18:0 & $8.185 \pm 0.341$ & $4.516 \pm 0.235$ & $22: 4 n-6$ & $0.192 \pm 0.015$ & $0.112 \pm 0.012$ \\
\hline $20: 0$ & $0.281 \pm 0.011$ & $0.152 \pm 0.006$ & $\sum n-6$ & $8.414 \pm 0.400$ & $4.821 \pm 0.309$ \\
\hline$\Sigma$ SFA & $27.934 \pm 0.416$ & $16.738 \pm 1.039$ & & & \\
\hline 12:0, 11-methyl & $0.023 \pm 0.003$ & $0.017 \pm 0.003$ & $18: 3 n-3$ & $0.919 \pm 0.089$ & $0.555 \pm 0.071$ \\
\hline 13:0, 3-methyl & $0.015 \pm 0.001$ & $0.008 \pm 0.001$ & $18: 4 n-3$ & $0.275 \pm 0.030$ & $0.194 \pm 0.039$ \\
\hline 13:0, 12-methyl & $0.035 \pm 0.004$ & $0.025 \pm 0.004$ & $18: 5 n-3$ & $0.232 \pm 0.035$ & $0.144 \pm 0.032$ \\
\hline 14:0, 13-methyl & $0.145 \pm 0.016$ & $0.100 \pm 0.015$ & $20: 3 n-3$ & $0.099 \pm 0.006$ & $0.057 \pm 0.005$ \\
\hline 14:0, 12-methyl & $0.095 \pm 0.010$ & $0.063 \pm 0.009$ & $20: 4 n-3$ & $0.171 \pm 0.013$ & $0.102 \pm 0.011$ \\
\hline 15:0, 14-methyl & $0.149 \pm 0.015$ & $0.098 \pm 0.013$ & $20: 5 n-3$ & $17.287 \pm 0.772$ & $9.423 \pm 0.507$ \\
\hline 15:0, 13-methyl & $0.047 \pm 0.003$ & $0.027 \pm 0.002$ & $21: 5 n-3$ & $0.144 \pm 0.010$ & $0.086 \pm 0.010$ \\
\hline 16:0, 15-methyl & $0.373 \pm 0.038$ & $0.234 \pm 0.031$ & $22: 5 n-3$ & $0.462 \pm 0.037$ & $0.275 \pm 0.033$ \\
\hline 16:0, 14-methyl & $0.348 \pm 0.037$ & $0.210 \pm 0.026$ & $22: 6 n-3$ & $0.810 \pm 0.076$ & $0.496 \pm 0.067$ \\
\hline 17:0, 16-methyl & $0.103 \pm 0.009$ & $0.061 \pm 0.007$ & $\sum n-3$ & $20.449 \pm 0.870$ & $11.367 \pm 0.654$ \\
\hline 17:0, 15-methyl & $0.085 \pm 0.006$ & $0.046 \pm 0.003$ & & & \\
\hline 16:1, 7-methyl & $0.140 \pm 0.013$ & $0.086 \pm 0.010$ & $16: 2 n-4$ & $0.122 \pm 0.024$ & $0.104 \pm 0.033$ \\
\hline Phytanic acid & $0.068 \pm 0.009$ & $0.041 \pm 0.007$ & $16: 3 n-4$ & $0.066 \pm 0.017$ & $0.058 \pm 0.022$ \\
\hline$\sum$ BCFA & $1.628 \pm 0.136$ & $1.016 \pm 0.117$ & $17: 2 n-5$ & $0.125 \pm 0.019$ & $0.082 \pm 0.018$ \\
\hline & & & $20: 2 n-7$ & $0.150 \pm 0.009$ & $0.086 \pm 0.008$ \\
\hline $14: 1 n-5$ & $0.150 \pm 0.012$ & $0.101 \pm 0.015$ & $22: 2 \Delta 5,13$ & $0.183 \pm 0.014$ & $0.107 \pm 0.012$ \\
\hline $16: 1 n-9$ & $7.958 \pm 0.583$ & $5.392 \pm 0.821$ & $\Sigma$ other PUFA & $0.645 \pm 0.054$ & $0.437 \pm 0.070$ \\
\hline $17: 1 \mathrm{n}-7$ & $1.293 \pm 0.114$ & $0.784 \pm 0.108$ & & & \\
\hline $18: 1 n-9+n-7$ & $29.834 \pm 0.824$ & $16.523 \pm 0.710$ & $\sum$ PUFA & $29.508 \pm 0.891$ & $16.624 \pm 0.824$ \\
\hline $19: 1 n-9$ & $0.425 \pm 0.034$ & $0.246 \pm 0.030$ & & & \\
\hline $20: 1 n-9+n-7$ & $1.272 \pm 0.131$ & $0.816 \pm 0.124$ & $n-6 / n-3$ & $0.535 \pm 0.055$ & $0.535 \pm 0.055$ \\
\hline$\sum$ MUFA & $40.931 \pm 0.825$ & $23.862 \pm 1.315$ & Total FA & & $58.240 \pm 2.937$ \\
\hline
\end{tabular}

${ }^{1} n-6 / n-3$ ratio was calculated as the mean of ratios from each sample.

${ }^{2}$ BCFA = branched chain fatty acids; DW = dry weight; MUFA = monounsaturated fatty acids; PUFA = polyunsaturated fatty acids; SE = standard error; SFA = saturated fatty acids 
Saturated fatty acids (SFA) comprised $28 \%$ of the profile, with 16:0 being the most abundant of the SFA and the third most abundant in the total fatty acid profile (17\%). Monounsaturated fatty acids (MUFA) constituted $41 \%$ of the profile, dominated by 18 carbons long fatty acids (18:1 n-9 and n-7), representing $30 \%$ of the total. PUFA exhibited high content (30\%) and diversity, with twentytwo different fatty acids being identified. Among these, the most abundant contained 20 carbon atoms: 20:5 n-3 (EPA, $17 \%$ ) and 20:4 n-6 (arachidonic acid, 4\%). Total n-6 and n-3 averaged around $8 \%$ and $20 \%$, respectively, resulting in a low $n-6 / n-3$ ratio (around 0.4 to 0.5 ; Table 1 ). Diversity was also higher in the $n-3$ family (10 fatty acids), with a length between 16 and 22 carbons. Other PUFA families identified include $n-7, n-4$ and $n-5$. Lastly, 13 BCFA were detected (1.6\% of the profile), including iso- and anteiso-(mono) methyl BCFA, an unsaturated branched-chain (7-methyl6-hexadecenoic acid) and the (poly)methyl phytanic acid (3,7,11,15-tetramethylhexadecanoic acid). While the FA profile mostly consists of even-carbon chains, odd-chain fatty acids represent a considerable portion of the total ( $\approx 3.8 \%)$, especially 17 carbon fatty acids.

Concerning the fatty acid content, $100 \mathrm{mg}$ of $M$. maritimae meal would provide, on average, $5.8 \mathrm{mg}$ of fatty acids. Of these, $1.7 \mathrm{mg}$ are PUFA, of which $1.1 \mathrm{mg}$ is $\mathrm{n}-3$. The average fatty acid profile of $M$. maritimae, recorded in each sampling site, is summarised in Table 2.

\section{Statistical analysis}

The dominant fatty acids present in the flies were roughly the same across the different sites, albeit with differences in their relative contributions. The ANOSIM test revealed these differences to be highly significant (Global $\mathrm{R}=0.342$, $P<0.001$ ). The relatively low value of $R$ denotes high natural variability within groups (samples from the same site), with some overlap between them. Thus, not all sites were found to be different in the subsequent pair-wise comparisons (Table 3).

Reboxo was statistically different from all the others, while Cacia differed from all locations except Triângulo. The remaining five sites were not statistically distinct, with the exception of Salinas and Triângulo $(P<0.001)$. Between site dissimilarity is mostly explained by 18:1 and 20:5 n-3 (EPA), according to the SIMPER results (Supplementary Material Table S1). Other relevant fatty acids are 16:1, 16:0 and 18:0, that were not only the most abundant, but also had the highest standard deviations (Tables 1 and Supplementary Material Table S1).

The proportions of each fatty acid varied along the landscape. The differences observed between Cacia and the other sites were mainly due to the lower levels of 20:5 $\mathrm{n}-3(7.7 \pm 3.3 \%)$ in this site, accompanied by an increase in $18: 1(\approx 38 \%)$. In Reboxo, levels of $18: 1$ were also high

Table 2. M. maritimae fatty acid characterisation per study site, expressed as relative abundances $(\%) \pm \mathrm{SE}$. Sample mean weight (mg) $\pm \mathrm{SE}$ is provided in the first table row. Only the top contributing fatty acids are shown in the table (average abundance $>0.5 \%$ ). ${ }^{1}$

\begin{tabular}{|c|c|c|c|c|c|c|c|}
\hline & $\operatorname{Bico}(n=10)$ & Cacia $(n=5)$ & Farinha $(n=5)$ & Reboxo $(n=20)$ & Rio Novo $(n=5)$ & Salinas $(n=15)$ & Triângulo $(n=14)$ \\
\hline Weight (mg) & $0.8 \pm 0.1$ & $1.5 \pm 0.1$ & $1.1 \pm 0.2$ & $1.6 \pm 0.1$ & $1.3 \pm 0.2$ & $1.0 \pm 0.1$ & $1.4 \pm 0.1$ \\
\hline $14: 0$ & $0.5 \pm 0.1$ & $0.6 \pm 0.0$ & $1.2 \pm 0.2$ & $0.7 \pm 0.0$ & $0.6 \pm 0.1$ & $0.5 \pm 0.1$ & $1.9 \pm 0.4$ \\
\hline $16: 0$ & $13.8 \pm 0.9$ & $19.1 \pm 0.8$ & $17.2 \pm 1.2$ & $20.2 \pm 0.9$ & $16.1 \pm 1.4$ & $14.1 \pm 0.7$ & $18.1 \pm 1.1$ \\
\hline $16: 1$ & $4.7 \pm 0.3$ & $12.4 \pm 0.6$ & $5.8 \pm 0.3$ & $8.8 \pm 0.3$ & $6.1 \pm 1.1$ & $4.9 \pm 0.5$ & $12.2 \pm 1.7$ \\
\hline $17: 0$ & $1.6 \pm 0.3$ & $0.4 \pm 0.1$ & $1.3 \pm 0.2$ & $0.5 \pm 0.0$ & $1.3 \pm 0.2$ & $1.5 \pm 0.1$ & $0.8 \pm 0.1$ \\
\hline $17: 1$ & $2.0 \pm 0.5$ & $0.5 \pm 0.1$ & $1.3 \pm 0.1$ & $0.9 \pm 0.0$ & $1.4 \pm 0.1$ & $1.5 \pm 0.1$ & $1.3 \pm 0.1$ \\
\hline 18:0 & $10.4 \pm 0.7$ & $7.1 \pm 0.3$ & $9.0 \pm 0.4$ & $5.8 \pm 0.2$ & $9.7 \pm 1.0$ & $10.9 \pm 0.5$ & $6.7 \pm 0.5$ \\
\hline 18:1 & $27.3 \pm 0.9$ & $38.3 \pm 0.9$ & $23.6 \pm 2.4$ & $35.1 \pm 0.3$ & $30.8 \pm 2.4$ & $27.3 \pm 1.4$ & $25.6 \pm 2.0$ \\
\hline $18: 2 n-6$ & $3.2 \pm 0.3$ & $4.4 \pm 0.4$ & $2.8 \pm 0.4$ & $2.7 \pm 0.2$ & $2.9 \pm 0.5$ & $3.1 \pm 0.2$ & $4.2 \pm 0.6$ \\
\hline $18: 3 n-3$ & $0.9 \pm 0.1$ & $0.4 \pm 0.1$ & $1.3 \pm 0.2$ & $0.6 \pm 0.0$ & $0.7 \pm 0.1$ & $1.1 \pm 0.1$ & $1.4 \pm 0.3$ \\
\hline $20: 1$ & $1.0 \pm 0.1$ & $0.6 \pm 0.1$ & $2.5 \pm 0.6$ & $0.9 \pm 0.1$ & $1.5 \pm 0.5$ & $1.6 \pm 0.2$ & $1.4 \pm 0.3$ \\
\hline $20: 4 n-6$ & $4.0 \pm 0.4$ & $4.4 \pm 0.4$ & $4.1 \pm 0.7$ & $4.0 \pm 0.3$ & $3.4 \pm 0.3$ & $3.8 \pm 0.2$ & $4.5 \pm 0.5$ \\
\hline $20: 5 n-3$ & $22.4 \pm 1.3$ & $7.7 \pm 1.5$ & $19.3 \pm 1.0$ & $15.0 \pm 0.8$ & $18.4 \pm 1.3$ & $22.2 \pm 1.0$ & $14.0 \pm 1.8$ \\
\hline $22: 6 n-3$ & $1.0 \pm 0.1$ & $0.2 \pm 0.1$ & $1.7 \pm 0.4$ & $0.5 \pm 0.0$ & $0.8 \pm 0.1$ & $1.1 \pm 0.1$ & $0.7 \pm 0.1$ \\
\hline BCFA & $1.4 \pm 0.1$ & $1.1 \pm 0.1$ & $2.7 \pm 0.6$ & $1.4 \pm 0.1$ & $2.3 \pm 0.9$ & $1.4 \pm 0.2$ & $1.9 \pm 0.3$ \\
\hline Others & $5.8 \pm 0.7$ & $2.7 \pm 0.2$ & $6.2 \pm 1.0$ & $3.0 \pm 0.1$ & $3.9 \pm 0.3$ & $5.0 \pm 0.3$ & $5.4 \pm 0.5$ \\
\hline
\end{tabular}

${ }^{1}$ BCFA = branched chain fatty acids; SE = standard error. 
Table 3. Results from the ANOSIM pairwise comparisons between sites.

$\begin{array}{lcr}\text { Paired sites } & \text { R statistic } & \text { P-value } \\ \text { Bico, Cacia } & & \\ \text { Bico, Farinha } & 0.777 & <0.001 \\ \text { Bico, Reboxo } & 0.179 & 0.095 \\ \text { Bico, Rio Novo } & 0.648 & <0.001 \\ \text { Bico, Salinas } & 0.057 & 0.297 \\ \text { Bico, Triangulo } & -0.04 & 0.698 \\ \text { Cacia, Farinha } & 0.116 & 0.062 \\ \text { Cacia, Reboxo } & 0.836 & 0.008 \\ \text { Cacia, Rio Novo } & 0.404 & 0.004 \\ \text { Cacia, Salinas } & 0.476 & 0.016 \\ \text { Cacia, Triangulo } & 0.734 & <0.001 \\ \text { Farinha, Reboxo } & -0.107 & 0.776 \\ \text { Farinha, Rio Novo } & 0.706 & <0.001 \\ \text { Farinha, Salinas } & -0.008 & 0.452 \\ \text { Farinha, Triangulo } & 0.111 & 0.123 \\ \text { Reboxo, Rio Novo } & -0.117 & 0.826 \\ \text { Reboxo, Salinas } & 0.341 & 0.021 \\ \text { Reboxo, Triangulo } & 0.565 & <0.001 \\ \text { Rio Novo, Salinas } & 0.389 & <0.001 \\ \text { Rio Novo, Triangulo } & 0.054 & 0.282 \\ \text { Salinas, Triangulo } & -0.145 & 0.903 \\ & 0.234 & <0.001 \\ & & \end{array}$

$(\approx 35 \%)$ but the content in EPA was twice as much as in Cacia $(\approx 15 \%)$. By contrast, samples from Bico and Salinas had the highest content in EPA $(\approx 22 \pm 4 \%)$. Some flies from Bico had maximum abundances of EPA, up to $30 \%$. The $\mathrm{n}-6 / \mathrm{n}-3$ ratio was, on average, 0.5 . However, it should be noted the very high variability between samples, even within groups, with many shorter fatty acids being almost absent from most samples.

\section{Discussion}

This study is the first characterisation of the fatty acid profile of a dolichopodid fly. A wide diversity of fatty acids was identified in $M$. maritimae, particularly of methyl-branched with less than 16 carbons and PUFA of varying length and unsaturation degree. From the latter, the diversity and high abundance of n-3 fatty acids is of particular interest to ensure the good condition of captive fish (Bou et al., 2017; Henry et al., 2015).

Concerning the dietary value of $M$. maritimae, this insect can be considered as an interesting source of n-3 PUFA $(11 \mu \mathrm{g} / \mathrm{mg}$ DW), namely EPA. A relative abundance of $\mathrm{n}-3$ fatty acids up to $20 \%$ or more is well above that recorded for other insects currently used in aquafeeds, such as Hermetia illucens (black soldier fly). Even when H. illucens was supplemented with fish offal or fishmeal, n-3 fatty acids comprised only 4 and $5.3 \%$ of the fatty acid profile, respectively (Barroso et al., 2017; St-Hilaire et al., 2007). Whenever higher values for these fatty acids were reported, a negative trade-off occurred in the form of reduced growth and nutritional imbalances (Liland et al., 2017).

The fatty acid profile of $M$. maritimae is richer in $\mathrm{n}-3$ fatty acids than other insects currently investigated for aquafeeds (Nogales-Mérida et al., 2019), but it is rather comparable to that of other semi-aquatic insects. For instance, freshwater insects can exhibit values of total $\mathrm{n}-3$ ranging from 20 to 30\% (Bell et al., 1994; Sushchik et al., 2013). However, in some species, much of the n-3 PUFA content corresponds to alpha-linolenic (18:3 n-3, or ALA) (Bell et al., 1994; Ghioni et al., 1996). In M. maritimae however, the main $\mathrm{n}-3$ PUFA was EPA, which is known to be required in the diet of marine organisms (Henry et al., 2015), due to their low conversion efficiency from ALA. Another issue, regarding the conversion of fatty acids, is the enzymatic competition with the $\mathrm{n}-6$ family (Lee et al., 2016). Nevertheless, the lipids of $M$. maritimae were low in n- 6 fatty acids, and the main one from this group was the arachidonic acid (20:4 $\mathrm{n}-6)$, also a LC-PUFA. By contrast, the precursor linoleic acid $(18: 2 n-6)$ is usually the main PUFA in terrestrial food sources, including insects (Bayes et al., 2014; Fontaneto et al., 2011; Nogales-Mérida et al., 2019; Yang et al., 2006).

The branched fatty acids, both saturated and unsaturated, iso and anteiso, are typically associated with bacterial sources (Meziane et al., 1997; Tsunoda et al., 2017) but can sometimes be synthetised by insects (Blomquist et al., 1994; Finck et al., 2016). We also recorded the presence of C16 n-4 PUFA, a typical diatom marker, and 18:5 n-3, which is associated with dinoflagellates (Dalsgaard et al., 2003; Dunstan et al., 1993; Ricardo et al., 2017; Zhukova, 1995). However, since these fatty acids were present in low quantities, the microalgal communities were most likely dominated by other microalgal taxa, such as cryptophytes, prymnesiophytes and green microalgae (Dalsgaard et al., 2003; Rossi et al., 2006; Sushchik et al., 2013). M. maritimae are evidently part of the estuarine trophic chain, as revealed by these fatty acid trophic markers, presumably as consumers of small invertebrates.

Traces of phytanic acid were also recorded, which is a byproduct of chlorophyll digestion, highly associated with both herbivory and herbivore-consumption (van den Brink and Wanders, 2006). In contrast, long chain SFA (e.g. 22:0, 24:0), which are characteristic of terrestrial plants, including Salicornia ramosissima, Halimione portucaloides (Maciel et al., 2018) and Spartina maritima (Bergamino et al., 2014), were not found. The presence of these fatty acids could imply direct consumption of the plants where the species was found, but that was not the case. This information may help clarify the trophic ecology of $M$. maritimae. Dolichopodids are classically predators of aquatic larvae 
and other insects (Miller et al., 2008). This hypothesis is reinforced by the lower levels of EPA in the individuals collected furthest away from sea water, in Cacia (Figure 1), where flies would be restricted to terrestrial insect prey. Consumption of macroalgae by adult flies seems unlikely, since adults were collected in the vegetation and the fatty acid profile is fairly distinct from seaweed flies (Biancarosa et al., 2018). On the other end, our results suggest that the larval stages may feed on decomposing organic matter of aquatic (likely algal) origin, thus explaining the presence of bacterial and microbial trophic markers.

The MUFA portion of M. maritimae seem to be less informative. Despite oleic acid being often used as a trophic marker of carnivory in marine animals, microand macroalgae sometimes contain substantial amounts of this fatty acid (Dalsgaard et al., 2003). For instance, in seaweed flies, the dominant MUFA is 16:1 n-7 (Biancarosa et al., 2018), while values around $30 \%$ of $18: 1$ (n-9) have been reported in the black soldier fly (Barroso et al., 2017).

In M. maritimae, the $18: 1$ fatty acids appears to be associated to the reduced levels of PUFA, especially EPA, as seen in Cacia and Reboxo. The higher abundance of 18:1 in these sites may be explained by a compensatory effect, since insects assimilate PUFAs when available, but replace them with MUFA when these are scarce (Stanley-Samuelson et al., 1988). There seems to be a negative correlation, in insects, between MUFA (16:1 n-7 specifically) and PUFA (Bell et al., 1994).

Several PUFA routinely found in marine oils were also present in M. maritimae lipids, including n-7 FAs and 10 different n-3 PUFA, such as 16:4, 21:5 and DHA (Wasta and Mjøs, 2013).

Although it is possible that M. maritimae may be able to convert alpha-linolenic into EPA and DHA, as some insects can (Stanley-Samuelson et al., 1988), it is clear that this fatty acid profile results from the direct assimilation of dietary fatty acids. Additionally, a selective retaining effect may occur, resulting in elevated LC-PUFA content, especially when comparing with other insects.

Various fatty acids recorded in this study had never before been identified in insects, including 21:5 n-3 (heneicosapentaenoic acid) and 7-methyl-6-hexadecenoic acid. The discovery and quantification of these compounds was facilitated by the usage of the PARADISe tool. Because it analyses all samples simultaneously, provides a deconvoluted spectra for each chromatographic peak, enabling identification even on overlapping and/or low signal-to-noise ratio peaks (Johnsen et al., 2017). Yet, the inconsistent abundance of unusual fatty acids contributed to a high variability between individuals and is likely related to opportunistic feeding, a common trait in many amphibiotic insects (Williams, 1996). However, some variance can also be attributed to the natural heterogeneity among individuals collected in the wild, since these had different weights, age, sex and other uncontrolled factors, besides their trophic regime (Fontaneto et al., 2011; Nogales-Mérida et al., 2019).

The data provided in this study only concerns the fatty acid profile of adult flies, despite dipteran larvae being usually preferred as food or feed, both in the scientific and industrial applications. This preference arises from the higher dry mass of larvae (Liu et al., 2017) and from the chitin-based exoskeleton, further developed in adult insects, that is believed to impair digestion (Tran et al., 2015). However, studies with other insect species have frequently found a beneficial effect in defatting them, thus suggesting that the high saturated lipid content of larvae or prepupae may actually be detrimental (Henry et al., 2015; Tran et al., 2015). Chitin, in turn, can constitute an antinutrient, as it lowers protein digestibility (Dobermann $e t$ al. 2017). However, this is not always what occurs in marine fish, since these can digest chitin naturally present in dietary items in the wild, such as crustaceans and insects (Henry et al., 2015; Nogales-Mérida et al., 2019). In this sense, it is perhaps unadvised to overlook the potential use of adult insects as a valid alternative for aquafeeds.

By displaying a fatty acid profile poor in SFA and generally rich in EPA, as well as other PUFA, M. maritimae could potentially be a good alternative ingredient for marine aquafeeds. Moreover, the occupation of habitats in the vicinity of brackish and seawater seems to be determinant for the assimilation of dietary EPA by this fly. The high variability of its fatty acid profile indicates some dietary flexibility, hinting that with an appropriate substrate, $M$. maritimae could probably reach even higher levels of $n-3$ (and more consistently) than those observed in the wild. Another advantage of this species, and others present in European marine or coastal areas, is the opportunity to use native insects instead of the exotics ones, thus minimising the risks of unwanted introductions and disease spill-over (Vilcinskas, 2019). Furthermore, tropical insects require warmer environments, which ultimately represents an increase in production costs in temperate regions (Makkar et al., 2014).

\section{Conclusions}

This study presents for the first time the fatty acid profile of a dolichopodid. Furthermore, it shows that the coastal $M$. maritimae has a fatty acid profile rich in n-3 PUFA, albeit with some variation, which is to be expected from wild insects. However, it casts a light on the hidden potential of native marine and coastal insect biodiversity, which deserves more attention. 
On that regard, there are several crucial aspects that require further study: (1) the analysis of the fatty acid profile of larvae and pupae of this species; this would reveal if $n-3$ fatty acids are accumulated during the aquatic larval stages of the insect life cycle; (2) what is the larval primary food source (decomposing matter, benthonic algae, invertebrate prey, etc.); and (3) the difference between males and females.

However, the possibility that adult flies may continue to consume and accumulate fatty acids should not be discarded. For instance, in other insect species, PUFA play crucial roles during mating and oviposition periods (Stanley-Samuelson et al., 1988).

Despite this contribution to the knowledge on the ecology of $M$. maritimae, the next step would necessarily be to successfully rear the species in a laboratorial environment, which is evidently still far from an industrial scale operation. For now, several aspects of the ecology of $M$. maritimae remain unknown, making this task more difficult. While the industrial sector is funnelling towards few wellstudied species, thus limiting the options regarding food biodiversity, it may be pertinent to develop captive breeding of native insects as well.

The search for viable, sustainable aquafeed ingredients continues, but coastal insects, due to their high-quality lipids, may become an important part of the solution for the ongoing nutrient crisis currently impacting animal production worldwide, namely aquaculture.

\section{Acknowledgements}

We would like to thank Cátia Lima, Aldiro Pereira and Rui Marques for helping with the field sampling. Thanks are due to FCT/MCES for the financial support to CESAM (UIDB/50017/2020+UIDP/50017/2020) through national funds, and the co-funding by the FEDER, within the PT2020 Partnership Agreement and Compete 2020 and to QOPNA (FCT UID/QUI/00062/2019) and LAQV-REQUIMTE (UIDB/50006/2020), to the Portuguese Mass Spectrometry Network, (LISBOA-01-0145-FEDER-402-022125) to FCT/ MCTES through national funds (PIDDAC), and the cofunding by the FEDER, within the PT2020 Partnership Agreement and Compete 2020. Thanks are also due to project SUShI (CENTRO-01-0145-FEDER-030818), cofunded by Centro 2020 program, Portugal 2020, through the European Regional Development Fund, through the National Science Foundation (FCT/MCTES) and to the Integrated Programme of SR\&TD 'SmartBioR Smart Valorization of Endogenous Marine Biological Resources Under a Changing Climate' (Centro-01-0145FEDER-000018), co-funded by Centro 2020 program, PT2020, EU, through the European Regional Development Fund. OMCCA is funded by national funds (OE), through $\mathrm{FCT}$, in the scope of the framework contract foreseen in the numbers 4, 5 and 6 of the article 23, of the Decree-Law 57/2016, of August 29, changed by Law 57/2017, of July 19.

\section{Conflict of interest}

The authors declare no conflict of interest.

\section{Supplementary material}

Supplementary material can be found online at https://doi. org/10.3920/JIFF2020.0112.

Table S1. Between sites fatty acid profile dissimilarity and main contributors to dissimilarities. Only statistically relevant comparisons are shown.

\section{References}

Ameixa, O.M.C.C., Duarte, P.M. and Rodrigues, D.P., 2020. Insects, food security and sustainable aquaculture. In: Leal-Filho, W., Azul, A., Brandli, L., Özuyar, P. and Wall, T. (eds.) Zero hunger. Encyclopedia of the UN Sustainable Development Goals. Springer Nature, Cham, Switzerland, pp. 1-11. https://doi.org/10.1007/9783-319-69626-3_111-1

Anderson, M.J. and Walsh, D.C.I., 2013. PERMANOVA, ANOSIM, and the Mantel test in the face of heterogeneous dispersions: what null hypothesis are you testing? Ecological Monographs 83: 557-574. https://doi.org/10.1890/12-2010.1

Anderson, M.J., Gorley, R.N. and Clarke, K.R., 2008. PERMANOVA+ for PRIMER: guide to software and statistical methods. PRIMER-E, Plymouth, UK, 214 pp.

Asensi, A. and Diez-Garretas, B., 2017. Coastal vegetation. In: Loidi, J. (ed.) The vegetation of the Iberian Peninsula. Springer, Cham, Switzerland, pp. 397-432. https://doi.org/10.1007/978-3-319-548678_8

Aued-Pimentel, S., Lago, J.H.G., Chaves, M.H. and Kumagai, E.E., 2004. Evaluation of a methylation procedure to determine cyclopropenoids fatty acids from Sterculia striata St. Hil. Et Nauds seed oil. Journal of Chromatography A 1054: 235-239. https://doi.org/10.1016/j. chroma.2004.07.090

Barroso, F.G., De Haro, C., Sánchez-Muros, M.J., Venegas, E., MartínezSánchez, A. and Pérez-Bañón, C., 2014. The potential of various insect species for use as food for fish. Aquaculture 422: 193-201. https://doi.org/10.1016/j.aquaculture.2013.12.024

Barroso, F.G., Sánchez-Muros, M.-J., Segura, M., Morote, E., Torres, A., Ramos, R. and Guil, J.-L., 2017. Insects as food: enrichment of larvae of Hermetia illucens with omega 3 fatty acids by means of dietary modifications. Journal of Food Composition and Analysis 62: 8-13. https://doi.org/10.1016/j.jfca.2017.04.008

Bayes, S.K., Hellerstein, M.K., Fitch, M., Mills, N.J. and Welter, S.C., 2014. You are what you eat: fatty acid profiles as a method to track the habitat movement of an insect. Oecologia 175: 1073-1080. https://doi.org/10.1007/s00442-014-2976-9 
Belghit, I., Liland, N.S., Gjesdal, P., Biancarosa, I., Menchetti, E., Li, Y., Waagbø, R., Krogdahl, Å. and Lock, E.-J., 2019. Black soldier fly larvae meal can replace fish meal in diets of sea-water phase Atlantic salmon (Salmo salar). Aquaculture 503: 609-619. https:// doi.org/10.1016/j.aquaculture.2018.12.032

Bell, J.G., Ghioni, C. and Sargent, J.R., 1994. Fatty acid compositions of 10 freshwater invertebrates which are natural food organisms of Atlantic salmon parr (Salmo salar): a comparison with commercial diets. Aquaculture 128: 301-313. https://doi.org/10.1016/00448486(94)90319-0

Bergamino, L., Dalu, T. and Richoux, N.B., 2014. Evidence of spatial and temporal changes in sources of organic matter in estuarine sediments: stable isotope and fatty acid analyses. Hydrobiologia 732: 133-145. https://doi.org/10.1007/s10750-014-1853-1

Biancarosa, I., Liland, N.S., Day, N., Belghit, I., Amlund, H., Lock, E.-J. and Gilburn, A.S., 2018. The chemical composition of two seaweed flies (Coelopa frigida and Coelopa pilipes) reared in the laboratory. Journal Insects as Food Feed 4: 135-142. https://doi. org/10.3920/JIFF2018.0008

Blomquist, G.J., Guo, L., Gu, P., Blomquist, C., Reitz, R.C. and Reed, J.R., 1994. Methyl-branched fatty acids and their biosynthesis in the housefly, Musca domestica L. (Diptera: Muscidae). Insect Biochemistry and Molecular Biology 24: 803-810. https://doi. org/10.1016/0965-1748(94)90108-2

Bou, M., Berge, G.M., Baeverfjord, G., Sigholt, T., Østbye, T.-K. and Ruyter, B., 2017. Low levels of very-long-chain n-3 PUFA in Atlantic salmon (Salmo salar) diet reduce fish robustness under challenging conditions in sea cages. Journal of Nutritional Science 6: e32. https:// doi.org/10.1017/jns.2017.28

Clarke, K.R. and Gorley, R.N. (2006) PRIMER v6: user manual/tutorial (Plymouth routines in multivariate ecological research). PRIMER-E, Plymouth, UK, 192 pp.

d'Assis Fonseca, E.C.M., 1978. Diptera: Orthorrhapha, Brachycera, Dolichopodidae, handbooks for the identification of British insects. Royal Entomological Society of London, London, UK, 90 pp. https:// doi.org/10.1111/j.194.6-150X.1940.tb00204.x

Dalsgaard, J., St. John, M., Kattner, G., Müller-Navarra, D. and Hagen, W., 2003. Fatty acid trophic markers in the pelagic marine environment. Advances in Marine Biology 46: 225-340. https://doi. org/10.1016/S0065-2881(03)46005-7

Dobermann, D., Swift, J.A. and Field, L.M., 2017. Opportunities and hurdles of edible insects for food and feed. Nutrition Bulletin 42: 293-308. https://doi.org/10.1111/nbu.1229

Dunstan, G.A., Volkman, J.K., Barrett, S.M., Leroi, J.-M. and Jeffrey, S.W., 1993. Essential polyunsaturated fatty acids from 14 species of diatom (Bacillariophyceae). Phytochemistry 35: 155-161. https:// doi.org/10.1016/S0031-9422(00)90525-9

Finck, J., Berdan, E.L., Mayer, F., Ronacher, B. and Geiselhardt, S., 2016. Divergence of cuticular hydrocarbons in two sympatric grasshopper species and the evolution of fatty acid synthases and elongases across insects. Scientific Reports 6: 33695. https://doi. org/10.1038/srep33695

Folch, J., Lees, M. and Sloane Stanley, G.H., 1957. A simple method for the isolation and purification of total lipides from animal tissues. Journal of Biological Chemistry 226: 497-509.
Fontaneto, D., Tommaseo-Ponzetta, M., Galli, C., Risé, P., Glew, R.H. and Paoletti, M.G., 2011. Differences in fatty acid composition between aquatic and terrestrial insects used as food in human nutrition. Ecology of Food and Nutrition 50: 351-367. https://doi. org/10.1080/03670244.2011.586316

Food and Agriculture Organisation (FAO), 2020. The state of world fisheries and aquaculture 2020. Sustainability in action. FAO, Rome, Italy, 206 pp. https://doi.org/10.4060/ca9229en

Food and Agriculture Organisation / World Health Organisation (FAO/WHO), 2019. Hazards associated with animal feed. Report of the Joint FAO/WHO expert meeting. May 12-15, 2015. FAO, Rome, Italy, 265 pp. http://www.fao.org/3/ca6825en/ca6825en. pdf?eloutlink=imf2fao

Ghioni, C., Bell, J.G. and Sargent, J.R., 1996. Polyunsaturated fatty acids in neutral lipids and phospholipids of some freshwater insects. Comparative Biochemistry and Physiology Part B: Biochemistry and Molecular Biology 114: 161-170. https://doi.org/10.1016/03050491(96)00019-3

Happel, A., Czesny, S., Rinchard, J. and Hanson, S.D., 2017. Data pre-treatment and choice of resemblance metric affect how fatty acid profiles depict known dietary origins. Ecological Research 32: 757-767. https://doi.org/10.1007/s11284-017-1485-9

Henry, M., Gasco, L., Piccolo, G. and Fountoulaki, E., 2015. Review on the use of insects in the diet of farmed fish: past and future. Animal Feed Science and Technology 203: 1-22. https://doi.org/10.1016/j. anifeedsci.2015.03.001

Johnsen, L.G., Skou, P.B., Khakimov, B. and Bro, R., 2017. Gas chromatography - mass spectrometry data processing made easy. Journal of Chromatography A 1503: 57-64. https://doi.org/10.1016/j. chroma.2017.04.052

Lee, J., Lee, H., Kang, S. and Park, W., 2016. Fatty acid desaturases, polyunsaturated fatty acid regulation, and biotechnological advances. Nutrients 8: 23. https://doi.org/10.3390/nu8010023

Liland, N.S., Biancarosa, I., Araujo, P., Biemans, D., Bruckner, C.G., Waagbø, R., Torstensen, B.E. and Lock, E.-J., 2017. Modulation of nutrient composition of black soldier fly (Hermetia illucens) larvae by feeding seaweed-enriched media. PLoS ONE 12: e0183188. https://doi.org/10.1371/journal.pone.0183188

Lillebø, A., Ameixa, O., Sousa, L., Sousa, A., Soares, J., Dolbeth, M. and Alves, F., 2015. The physio-geographical background and the ecology of Ria de Aveiro. In: Lillebø, A., Stålnacke, P. and Gooch, G.D. (eds.) Coastal lagoons in Europe: integrated water resource strategies. International Water Association, London, UK, pp. 21-28.

Liu, X., Chen, X., Wang, H., Yang, Q., ur Rehman, K., Li, W., Cai, M., Li, Q., Mazza, L., Zhang, J., Yu, Z. and Zheng, L., 2017. Dynamic changes of nutrient composition throughout the entire life cycle of black soldier fly. PLoS ONE 12: e0182601. https://doi.org/10.1371/ journal.pone.0182601

Maciel, E., Lillebø, A., Domingues, P., Da Costa, E., Calado, R. and Domingues, M.R.M., 2018. Polar lipidome profiling of Salicornia ramosissima and Halimione portulacoides and the relevance of lipidomics for the valorization of halophytes. Phytochemistry 153: 94-101. https://doi.org/10.1016/j.phytochem.2018.05.015 
Makkar, H.P.S., Tran, G., Heuzé, V. and Ankers, P., 2014. Stateof-the-art on use of insects as animal feed. Animal Feed Science and Technology 197: 1-33. https://doi.org/10.1016/j. anifeedsci.2014.07.008

Meziane, T., Bodineau, L., Retiere, C. and Thoumelin, G., 1997. The use of lipid markers to define sources of organic matter in sediment and food web of the intertidal salt-marsh-flat ecosystem of MontSaint-Michel Bay, France. Journal of Sea Research 38: 47-58. https:// doi.org/10.1016/S1385-1101(97)00035-X

Miller, L.T., Stange, L., MacVean, C., Rey, J.R., Frank, J.H., Mizell, R.F., Heppner, J.B., Heppner, J.B., Capinera, J.L., Feir, D., Borgemeister, C., Hangay, G., Flowers, R.W., Heppner, J.B., Jaffe, K., Dietrich, C.H., Boucher, S., Heppner, J.B., Cranshaw, W., Cranshaw, W., Heppner, J.B., Behmer, S.T., Punzo, F., Boucias, D., Gayubo, S.F., Kima, P.E., Aldryhim, Y., Capinera, J.L., Calabrese, D.M., Heppner, J.B., Nation, J.L., Harman, D.M., Heppner, J.B., Wang, Q., Pollet, M.A.A., Brooks, S.E., Heppner, J.B., Leppla, N.C., Norris, D.E. and Heppner, J.B., 2008. Long-legged flies (Diptera: Dolichopodidae). In: Capinera, J.L. (ed.) Encyclopedia of entomology. Springer, Dordrecht, the Netherlands, pp. 2232-2241. https://doi.org/10.1007/978-1-4020-6359-6_2087

Nogales-Mérida, S., Gobbi, P., Józefiak, D., Mazurkiewicz, J., Dudek, K., Rawski, M., Kierończyk, B. and Józefiak, A., 2019. Insect meals in fish nutrition. Reviews in Aquaculture 11: 1080-1103. https:// doi.org/10.1111/raq.12281

Pollet, M., Andrade, R., Gonçalves, A., Andrade, P., Jacinto, V., Almeida, J., De Braekeleer, A., Van Calster, H. and Brosens, D., 2019. Dipterological surveys in Portugal unveil 200 species of long-legged flies, with over 170 new to the country (Diptera: Dolichopodidae). Zootaxa 4649: 1-69. https://doi.org/10.11646/zootaxa.4649.1.1

Popova, O.N., Haritonov, A.Y., Sushchik, N.N., Makhutova, O.N., Kalachova, G.S., Kolmakova, A.A. and Gladyshev, M.I., 2017. Export of aquatic productivity, including highly unsaturated fatty acids, to terrestrial ecosystems via Odonata. Science of the Total Environment 581: 40-48. https://doi.org/10.1016/j.scitotenv.2017.01.017

Ricardo, F., Maciel, E., Domingues, M.R. and Calado, R., 2017. Spatiotemporal variability in the fatty acid profile of the adductor muscle of the common cockle Cerastoderma edule and its relevance for tracing geographic origin. Food Control 81: 173-180. https://doi. org/10.1016/j.foodcont.2017.06.005

Ricardo, F., Pimentel, T., Moreira, A.S.P., Rey, F., Coimbra, M.A., Rosário Domingues, M., Domingues, P., Costa Leal, M. and Calado, R., 2015. Potential use of fatty acid profiles of the adductor muscle of cockles (Cerastoderma edule) for traceability of collection site. Scientific Reports. 5: 11125. https://doi.org/10.1038/srep11125

Rossi, S., Sabatés, A., Latasa, M. and Reyes, E., 2006. Lipid biomarkers and trophic linkages between phytoplankton, zooplankton and anchovy (Engraulis encrasicolus) larvae in the NW Mediterranean. Journal of Plankton Research 28: 551-562. https://doi.org/10.1093/ plankt/fbi140

Rumpold, B.A. and Schlüter, O.K., 2013. Potential and challenges of insects as an innovative source for food and feed production. Innovative Food Science and Emerging Technologies 17: 1-11. https://doi.org/10.1016/j.ifset.2012.11.005
Sánchez-Muros, M.-J., Barroso, F.G. and Manzano-Agugliaro, F., 2014. Insect meal as renewable source of food for animal feeding: a review. Journal of Cleaner Production 65: 16-27. https://doi.org/10.1016/j. jclepro.2013.11.068

Shahidi, F. and Ambigaipalan, P., 2018. Omega-3 polyunsaturated fatty acids and their health benefits. Annual Review of Food Science and Technology 9: 345-381. https://doi.org/10.1146/annurevfood-111317-095850

Stanley-Samuelson, D.W., Jurenka, R.A., Cripps, C., Blomquist, G.J. and De Renobales, M., 1988. Fatty acids in insects: composition, metabolism, and biological significance. Archives of Insect Biochemistry and Physiology 9: 1-33. https://doi.org/10.1002/ arch.940090102

St-Hilaire, S., Cranfill, K., McGuire, M.A., Mosley, E.E., Tomberlin, J.K., Newton, L., Sealey, W., Sheppard, C. and Irving, S., 2007. Fish offal recycling by the black soldier fly produces a foodstuff high in omega-3 fatty acids. Journal of the World Aquaculture Society 38: 309-313. https://doi.org/10.1111/j.1749-7345.2007.00101.x

Stoneham, T.R., Kuhn, D.D., Taylor, D.P., Neilson, A.P., Smith, S.A., Gatlin, D.M., Chu, H.S.S. and O'Keefe, S.F., 2018. Production of omega-3 enriched tilapia through the dietary use of algae meal or fish oil: improved nutrient value of fillet and offal. PLoS ONE 13: e0194241. https://doi.org/10.1371/journal.pone.0194241

Stork, N.E., 2018. How many species of insects and other terrestrial arthropods are there on Earth? Annual Review of Entomology 63: 31-45. https://doi.org/10.1146/annurev-ento-020117-043348

Sushchik, N.N., Gladyshev, M.I., Moskvichova, A.V., Makhutova, O.N. and Kalachova, G.S., 2003. Comparison of fatty acid composition in major lipid classes of the dominant benthic invertebrates of the Yenisei river. Comparative Biochemistry and Physiology - Part B: Biochemistry and Molecular Biology 134: 111-122. https://doi. org/10.1016/S1096-4959(02)00191-4

Sushchik, N.N., Yurchenko, Y.A., Gladyshev, M.I., Belevich, O.E., Kalachova, G.S. and Kolmakova, A.A., 2013. Comparison of fatty acid contents and composition in major lipid classes of larvae and adults of mosquitoes (Diptera: Culicidae) from a steppe region. Insect Science 20: 585-600. https://doi.org/10.1111/j.17447917.2012.01582.x

Tran, G., Heuzé, V. and Makkar, H.P.S., 2015. Insects in fish diets. Animal Frontiers 5: 37-44.

Tsunoda, T., Suzuki, J.-I. and Kaneko, N., 2017. Fatty acid analyses to detect the larval feeding preferences of an omnivorous soil-dwelling insect, Anomala cuprea (Coleoptera: Scarabaeidae). Applied Soil Ecology 109: 1-6. https://doi.org/10.1016/j.apsoil.2016.09.020

Twining, C.W., Shipley, J.R. and Winkler, D.W., 2018. Aquatic insects rich in omega-3 fatty acids drive breeding success in a widespread bird. Ecology Letters 21: 1812-1820. https://doi.org/10.1111/ ele. 13156

United Nations, Department of Economic and Social Affairs (UN DESA), 2017. World population prospects: the 2017 revision. Vol. I: comprehensive tables ST/ESA/SER.A/399. UN DESA, Population Division, New York, NY, USA. Available at: https:// population.un.org/wpp/Publications/Files/WPP2017_Volume-I_ Comprehensive-Tables.pdf 
Van den Brink, D.M. and Wanders, R.J.A., 2006. Phytanic acid: production from phytol, its breakdown and role in human disease. Cellular and Molecular Life Sciences 63: 1752-1765. https://doi. org/10.1007/s00018-005-5463-y

Van Huis, A., Van Itterbeeck, J., Klunder, H., Mertens, E., Halloran, A., Muir, G. and Vantomme, P., 2013. Edible insects: future prospects for food and feed security. FAO Forestry Paper no. 171. Food and Agriculture Organization of the United Nations (FAO), Rome, Italy, 187 pp. Available at: http://www.fao.org/docrep/018/i3253e/ i3253e.pdf.

Vilcinskas, A., 2019. Pathogens associated with invasive or introduced insects threaten the health and diversity of native species. Current Opinion in Insect Science 33: 43-48. https://doi.org/10.1016/j. cois.2019.03.004
Wasta, Z. and Mjøs, S.A., 2013. A database of chromatographic properties and mass spectra of fatty acid methyl esters from omega-3 products. Journal of Chromatography A 1299: 94-102. https://doi. org/10.1016/j.chroma.2013.05.056

Williams, D.D., 1996. Environmental constraints in temporary fresh waters and their consequences for the insect fauna. Journal of the North American Benthological Society 15: 634-650. https://doi. org/10.2307/1467813

Yang, L.F., Siriamornpun, S. and Li, D., 2006. Polyunsaturated fatty acid content of edible insects in Thailand. Journal of Food Lipids 13: 277-285. https://doi.org/10.1111/j.1745-4522.2006.00051.x

Zhukova, N., 1995. Fatty acid composition of 15 species of marine microalgae. Phytochemistry 39: 351-356. https://doi. org/10.1016/0031-9422(94)00913-E 